\title{
Copula model estimation and test of inventory portfolio pledge rate
}

\author{
Li Zhou ${ }^{1,}$, , Jing Dong ${ }^{2}$ \\ ${ }^{1}$ School of Information, Beijing Wuzi University, Beijing, China \\ ${ }^{2}$ Graduate department, Beijing Wuzi University, Beijing, China
}

\section{Email address:}

zhoulibit@126.com (Li Zhou)

\section{To cite this article:}

Li Zhou, Jing Dong. Copula Model Estimation and Test of Inventory Portfolio Pledge Rate. International Journal of Business and Economics Research. Vol. 3, No. 4, 2014, pp. 150-154. doi: 10.11648/j.ijber.20140304.12

\begin{abstract}
It chooses copper and zinc as a stock portfolio to pledge financing, and uses Clayton-Copula function as the joint density function of the two pledge portfolio. It uses K-S method for goodness of fit test whether the Copula function can correctly describe dependence structure between variables or not. Results show that there is a positive correlation between the two pledges, and the Clayton-Copula function is fitting effect for copper and zinc return correlation structure. The conclusion of this thesis lays the foundation for the following pledge rate calculation and portfolio risk analysis.
\end{abstract}

Keywords: Copula, Stock Portfolio, Pledge Rate, Parameter Estimation

\section{Introduction}

Inventory financing is still at the starting stage in our country, on the current scale, is still far from takes full advantage of rich resources inventory guarantee. Investigate its reason, mainly is the loan financing for inventory management technology is still relatively lacking. In the financing of the inventory, the research of the business of foreign scholars mainly focused on qualitative analysis, relatively less from the angle of quantitative analysis of inventory financing risk evaluation. Inventory financing originated from abroad, so there are many literatures on the basis of the problem, including the development history, business model and business process.

Inventory financing originated from abroad, so there are many literatures on the basis of the problem, including the development history, business model and business process.

With the exploration and innovation mode of logistics finance, China started to research on inventory financing, Rutberg (2002) [1] starting from the case, introduces the main characteristics of logistics financial mode. He takes corporation of UPS as a case, the company can supply including financing and risk management and a series of financial supply chain services, help enterprises to improve cash flow. Luo Qi (2002) [2] first defines the concept and operation mode of financing warehouse. Warehouse financing is a comprehensive third party logistics service platform, as the core of pledge material storage management, supervision, evaluation, public warehousing, and logistics distribution. At the same time also introduces two operation modes of financing storehouse obtain bank credit and the establishment of independent credit guarantee institutions. Zheng Jinbo (2003) [3] elaborated on the concept and business process of warehouse receipt pledge, analyzes warehouse receipt pledge advantages and risk, put forward focus of carrying out warehouse management of receipt pledge. Yu Yang (2003) [4] analyzes the origin and the importance of material bank, introduces two business models of rights pledge and flow goods pledge. In a word, there are many literatures research based on inventory financing pledge in the domestic, the scholars have gradually begun to study business risk, mostly qualitative classification and description of the risk, and then puts forward the risk control measures.

Fenmore (2004) [5] studies on the orders of financing business, suggest bank open a special payment account besides the general clearing households outside for the enterprise, and request the buyer of the enterprise issued the commitment letter which promises to order payment into the accounts of the bank, is easy to control the collection. Buzacott and Zhang (2004) [6] design corresponding indicators and quantitative research on the risk of inventory financing business. At the same time, they put the inventory mortgage financing as a function of assets and liabilities, according to the function to guide production activities and 
decision making.

With the exploration and innovation mode of logistics finance, China started to research on inventory financing, Ren Wenchao (2006)[7] published article and in-depth exposition on the material bank, discusses the use of production materials, inventory and goods of chattel pledge financing process, and clarify the business should be signed the relevant agreement by the banks, enterprises and storage enterprises three parties. Li Juan (2007) [8] from the point of operation research to analyze inventory pledge financing business risk, using the parameter function compares the phase of loans and one-time loans, points out phase loans than prior to one-time loan risk. Li Yixue(2007) [9] analyzes evolution of three foreign inventory financing process and two stage domestic inventory financing business, and summarized the characteristics of each process or stage, and aiming at the shortage of our inventory financing, and provides relevant countermeasures and suggestions.

By comparison, using the model to measure relationship between pledge price and the pledge rate is relatively seldom. For the calculation of stock portfolio, some scholars introduced Copula function to describe the pledge of price changes, and assume that the pledge price change obey normal Copula function, lack of analysis and verification whether collateral price changes consists with the normal Copula function or not; some scholars calculate the pledge rate of two collateral, which is based on assumption of two collateral price independent of each other.

\section{The Selection of Pledge and Copula Function}

\subsection{The Selection of Pledge}

This paper selects copper and zinc as a stock portfolio of mortgage financing. On the one hand, both in the spot market and futures market, each contract variety price is continuous, easy to collect and analysis. On the other hand, there is a certain correlation between the two kinds of non-ferrous metals market demand. Copper is widely used in automobile manufacturing, construction industry, machinery manufacturing, defense industry, light industry etc. Total consumption of zinc in approximately half of the proportion was used in galvanized industry, while zinc is also widely used in automobile manufacturing, ship building industry, light industry, etc. Zinc itself strength and hardness is not enough, so often join copper and other alloy elements, in order to improve the strength and hardness, which used in automotive, construction, electrical, mechanical manufacturing etc. The copper and zinc are also used in many industries, so when the demand for zinc is increased, the demand for copper will increase, leading to zinc prices rise, copper prices will rise; when the zinc demand reduction, the demand for copper will be reduced, resulting in zinc and copper prices will fall. Copper and zinc prices is not only affected by the political environment, market demand, industry policy, international market factors can influence of two kinds of product prices, therefore, the price trend will not be exactly the same, but has a strong correlation.

\subsection{The Preliminary Selection of Copula Function}

According to the January 1 to December 31 st in 2012, takes the highest price daily spot of $1 \#$ copper and $1 \#$ zinc, using SPSS software, draw the copper and zinc prices scatter diagram, as shown in "Fig. 1".

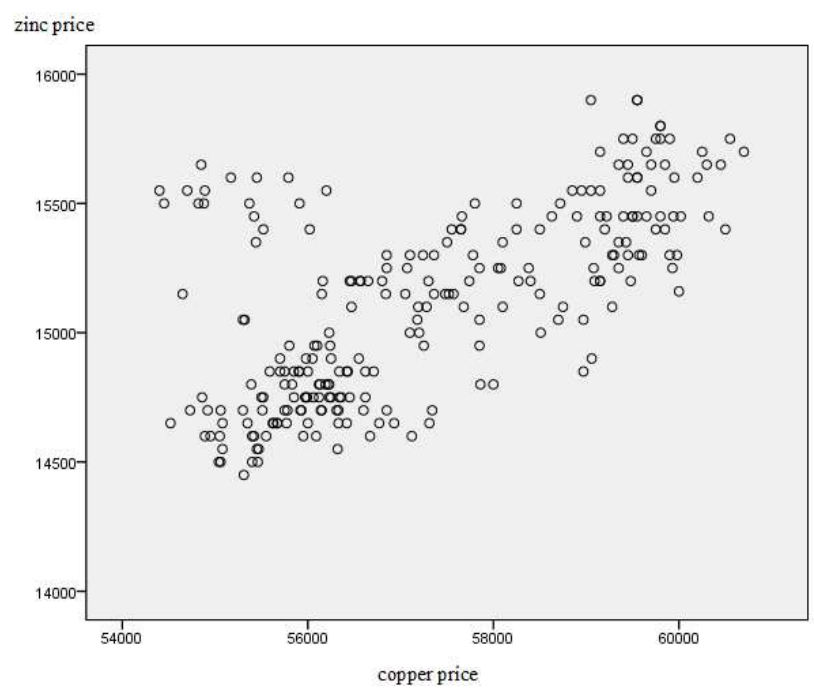

Figure 1. Copper and zinc prices scatter diagram.

Seen from Figure 1, two pledge prices in the tail is more intensive, and more concentrated in the lower tail of the distribution, indicates that the probability of the lower and higher pledge prices relatively large. Further, the scatter plot is compared with five kinds of Copula function distribution, we can draw such a conclusion, namely the price distribution of copper and zinc and Clayton Copula distribution is similar. Archimedes Copula function family coverage, to contain the most common binary Copula dependence structure, so we preliminary choose the Clayton Copula function as the joint density function of the two pledge portfolio.

\section{The Correlation Measure and Parameter Estimation}

\subsection{The Correlation Measures of Two Pledge Rate of Return}

The dependence structure of Copula function, Nelson has given the following theorem:

Strictly monotone increasing transform random variables $\left(x_{1}, x_{2}, \cdots x_{n}, \cdots, x_{N}\right)$, the Copula function unchanged, that is $\frac{\partial f_{n}(x)}{\partial x}>0$, then $C_{x_{1}, x_{2}, \cdots x_{n}, \cdots, x_{N}}=$ 
$C_{f_{1}\left(x_{1}\right), f_{2}\left(x_{2}\right), \cdots, f_{n}\left(x_{n}\right) \cdots f_{N}\left(x_{N}\right)}$, where $C_{x_{1}, x_{2}, \cdots x_{n}, \cdots, x_{N}}$ represents the Copula function connection with $\left(x_{1}, x_{2}, \cdots x_{n}, \cdots, x_{N}\right), C_{f_{1}\left(x_{1}\right), f_{2}\left(x_{2}\right), \cdots, f_{n}\left(x_{n}\right) \cdots f_{N}\left(x_{N}\right)}$ represents the Copula function connection with $\left(f_{1}\left(x_{1}\right), f_{2}\left(x_{2}\right), \cdots, f_{n}\left(x_{n}\right) \cdots f_{N}\left(x_{N}\right)\right)$.

The correlation indicators derived from Copula function are strictly monotone increasing correlation transform, which widens the range of correlation, not only on the linear correlation, and can get the relationship between the correlation coefficient and the corresponding Copula function by the above theorem, method of correlation measure specific Kendall correlation coefficient and Spearman correlation coefficient.

(1) Kendall correlation coefficient

Assume $\left(x_{1}, y_{1}\right),\left(x_{2}, y_{2}\right)$ are vectors of independent and identically distributed, $x_{1}, x_{2} \in x, y_{1}, y_{2} \in y$, let

$$
\tau=p\left[\left(x_{1}-x_{2}\right)\left(y_{1}-y_{2}\right)>0\right]-p\left[\left(x_{1}-x_{2}\right)\left(y_{1}-y_{2}\right)<0\right] \text {. }
$$

We can prove that $\tau=2 p\left[\left(x_{1}-x_{2}\right)\left(y_{1}-y_{2}\right)>0\right]-1$.

Let $C(u, v)$ denotes Copula function of $\mathrm{X}$ and $\mathrm{Y}$ respectively, then

$$
\tau=4 \iiint_{0 \leq u, v \leq 1} C(u, v) d C(u, v)-1
$$

Then it can calculate Kendall correlation coefficient by formula (2) listed in "Tab. 1" below.

Table 1. Kendall correlation coefficient

\begin{tabular}{cccc}
\hline \multicolumn{2}{c}{ Kendall } & 1\# Zinc yield & 1\# Copper yield \\
\hline \multirow{2}{*}{ 1\# Zinc yield } & $\begin{array}{c}\text { correlation } \\
\text { coefficient } \\
\mathrm{N}\end{array}$ & 1.000 & .356 \\
$\begin{array}{c}\text { 1\# Copper } \\
\text { yield }\end{array}$ & $\begin{array}{c}\text { correlation } \\
\text { coefficient } \\
\mathrm{N}\end{array}$ & 240 & 240 \\
\hline
\end{tabular}

We can see from table 1 , Kendall correlation coefficient of copper yield and zinc yield is 0.356 , the two pledge rate of return has positive correlation.

(2) Spearman correlation coefficient

Led Spearman correlation coefficient is $\rho$, then

$$
\begin{array}{r}
\rho=3\left(p\left(\left(X_{1}-X_{2}\right)\left(Y_{1}-Y_{3}\right)>0\right)\right. \\
\left.-p\left(\left(X_{1}-X_{2}\right)\left(Y_{1}-Y_{3}\right)<0\right)\right)
\end{array}
$$

Let $C(u, v)$ denotes Copula function of $\mathrm{X}$ and $\mathrm{Y}$ respectively, then

$$
\rho=12 \int_{0}^{1} \int_{0}^{1} u v d C(u, v)-3
$$

\begin{tabular}{|c|c|c|c|}
\hline \multicolumn{2}{|c|}{ Spearman } & 1\# Zinc yield & 1\# Copper yield \\
\hline \multirow{2}{*}{ 1\# Zinc yield } & $\begin{array}{l}\text { correlation } \\
\text { coefficient }\end{array}$ & 1.000 & .376 \\
\hline & $\mathrm{N}$ & 240 & 240 \\
\hline \multirow{2}{*}{ 1\# Copper yield } & $\begin{array}{l}\text { correlation } \\
\text { coefficient }\end{array}$ & .376 & 1.000 \\
\hline & $\mathrm{N}$ & 240 & 240 \\
\hline
\end{tabular}

Then it can calculate Spearman correlation coefficient by formula (4) listed in "Tab. 2" below.
Table 2. Spearman correlation coefficient

We can see from table 2, Spearman correlation coefficient of copper yield and zinc yield is 0.376 , the two pledge rate of return has positive correlation. Two correlation coefficients are consistent conclusion.

\subsection{Model Assumptions}

The model is built based on the following assumptions.

Hypothesis 1: using the spot 1 \# copper and $1 \#$ zinc as a combination of inventory portfolio financing, and financing in the loan period beginning $t=0 . p_{1,0}$ is the average price of $1 \#$ copper in time $t=0, p_{2,0}$ is the average price of $1 \#$ zinc in time $t=0, q_{1,0}$ is the number of $1 \#$ copper, $q_{2,0}$ is the number of $1 \#$ zinc, take bit as the number of units of pledge $\mathrm{t}=1$, and $q_{1,0}=q_{2,0}=1$.

Hypothesis 2: for a period of 1 years loans, bank loan interest rates unchanged during mortgage period;

Hypothesis 3: the good faith management of logistics enterprises, there is no risk of default.

Hypothesis 4: storage management costs negligible.

Hypothesis 5: do not consider the correlation of the spot 1\# copper and 1 \# zinc price;

Based on these assumptions, the calculation steps of Copula-VaR method is applied to the portfolio of inventory, will gradually be calculated.

\subsection{Parameter Estimation}

Make $\Theta$ as a parameter space, and $\theta$ as the n-dimension vector for prediction parameters. Order $L_{t}(\theta)$ and $l_{t}(\theta)$ were the likelihood function and the log-likelihood function of time $t$ observation, the $\log$ likelihood function is defined as

$$
l(\theta)=\sum_{t=1}^{T} l_{t}(\theta)
$$

1. Estimation of normal Copula function parameters

Let $\Theta=\left\{R: R \in \mathfrak{R}^{N \times N}\right\}$ denotes positive definite matrix the parameter space symmetric as $\mathrm{R}$, the normal Copula density using equation (5), then

$$
l(\theta)=-\frac{T}{2} \ln |R|-\frac{1}{2} \sum_{t=1}^{T} \xi_{t}^{\prime}\left(R^{-1}-I\right) \xi_{t} .
$$

2. Estimation of Archimedean Copula function 
parameters

Let $\theta=\left\{(v, R): v \in(2, \infty), R \in \mathfrak{R}^{N \times N}\right\}$ denotes positive definite matrix the parameter space symmetric as $\mathrm{R}$, the t-Copula density using equation (5), then

$$
l(\theta)=T \ln \frac{\Gamma\left(\frac{v+N}{2}\right)}{\Gamma\left(\frac{v}{2}\right)}-\frac{T}{2} \ln |R| .
$$

3. Estimation of Clayton Copula function parameters

The distribution function and the density function of the Clayton Copula function respectively are

$$
\begin{gathered}
C_{c}(u, v ; \theta)=\left(u^{-\theta}+v^{-\theta}-1\right)^{-1 / \theta} . \\
C_{c}(u, v ; \theta)=(1+\theta)(u v)^{-\theta-1}\left(u^{-\theta}+v^{-\theta}-1\right)^{-2-1 / \theta} .
\end{gathered}
$$

Where $\theta \in(0, \infty)$, denote relevant parameters. When $\theta \rightarrow 0$, random variables $\mathrm{u} 、 \mathrm{v}$ tend to be independent, that is $\lim _{\theta \rightarrow 0} C_{c}(u, v ; \theta)=u v$. When $\theta \rightarrow \infty$, random variables $\mathrm{u}$ 、 $\mathrm{v}$ tend to be perfectly correlated, and $\lim _{\theta \rightarrow \infty} C_{c}(u, v ; \theta)=\min (u, v)=C^{+}$, that is when $\theta \rightarrow \infty$, Clayton Copula function tend to the top limit $C^{+}$of Frechet .

For the Clayton Copula function, the related parameters have a property, namely there is corresponding relationship between related parameters $\theta$ and correlation and consistency of measurement value, such as Kendall correlation coefficient $\tau$ and the related parameters $\theta$ are the following correspondence:

$$
\tau_{C}=\theta /(\theta+2)
$$

According to table 1, Kendall correlation coefficient is 0.356 , bring it into the formula (10) to calculate the related parameters $\theta$ is 0.95 .

\section{Goodness of Fit Test of Copula Model}

Goodness of fit tests is to test whether the Copula function can correct description the dependence structure between variables. Based on Copula function theory, if $C(u, v)$ is a Copula function, where $u=F(x), v=G(y)$, $\mathrm{F}$ and $\mathrm{G}$, respectively, are the distribution function of random variables $\mathrm{X}$ and $\mathrm{Y}$, then the distribution function of random variable $\mathrm{Y}$ under the condition of $X=x$ is

$$
H(Y \leq y \mid X=x)=C_{1}(F(x), G(y)) .
$$

Where, $C_{1}(u, v)=\frac{\partial C(u, v)}{\partial u}$.

Because of $C_{1}(u, v)$ obey uniform distribution in $(0,1)$ interval, so it has one order partial derivative for the Copula function that also is the conditional distribution of Copula function, namely the inspection $C(u \mid v)$ and $C(u \mid v)$ whether obey uniform distribution in $(0,1)$ interval. The Copula function can fit variables well according to the structural inspection, operation method as follows: the sample data $\left(x_{i}, y_{i}\right), i=1,2, \cdots, n$ into $u=F(x), \quad v=G(y)$, get a group of data $\left\{C_{1 i}=C_{1}\left(F\left(x_{i}\right), G\left(y_{i}\right)\right)\right\}$, do K-S test method for the data set with uniform distribution, if the P-Value is high, the dependence structure of the Copula function fit effect is good. Test results are shown in "Tab. 3".

Table 3. P-value of Goodness of fit test

\begin{tabular}{ccc}
\hline Goodness of fit test & non parametric method & parametric method \\
\hline P-value & 0.0901 & 0.0542 \\
\hline
\end{tabular}

This paper used P-value for goodness of fit tests, test results as shown in table 3 , the significant level of 0.05 , the test of non parameter method and parameter method of $\mathrm{P}$-value are 0.0901 and 0.0542 , they all bigger than 0.05 , so that the Clayton Copula function fit better for the 1\# copper and $1 \#$ zinc yield correlation structure.

\section{Conclusion}

In the financing of the inventory, the research of the business of foreign scholars mainly focused on qualitative analysis, relatively less from the angle of quantitative analysis of inventory financing risk evaluation. This paper introduces Copula function to describe the pledge of price changes, and assume that the pledge price change obey normal Copula function. It selects copper and zinc as a stock portfolio of mortgage financing and preliminary choose the Clayton Copula function as the joint density function of the two pledge portfolio. After correlation measure and parameter estimation, the two pledge rate of return has positive correlation, and the Clayton Copula function fit better for the 1\# copper and 1\# zinc yield correlation structure. The conclusion of this thesis lays the foundation for the following pledge rate calculation and portfolio risk analysis.

\section{Acknowledgements}

The study is supported by Beijing Wuzi University scientific research base of science and technology innovation platform of modern logistics, information and control technology research (project code: PXM2014_014214_000086).

\section{References}

[1] Sidney Rutberg, "Financing the Supply Chain by Piggy-backing on the Massive Distribution Clout of United Parcel Service", The Secured lender, vol.58, pp.40-46, Jun.2002.

[2] Luo Qi, Zhu Daoli, Chen Boming, "Study on Logistics Service Innovation of financing warehouse and its operation mode third", China circulation economy, vol.2, pp. 11-14, Feb. 2002. 
[3] Zheng Jinbo, Qi Meizhi, "Warehouse receipt pledge and its management", Chinese logistics and procurement, vol.15,pp. 20-21, 2003.

[4] Yu Yang, Feng Genzhong, "Material bank business model and risk control research", Management review, vol.9, pp.5,2003.

[5] Eric Fenmore, "Making Purchase-Order Financing Work for You", The Secured Lender, vol.60, pp.20-24, Feb. 2004.

[6] Buzacott J. A. , R. Q. Zhang, "Inventory Management with Asset-Based Financing", Management Science, vol.24, pp.1274-1292, Sept. 2004.
[7] Ren Wenchao, "Application of material bank in supply chain", Logistics technology and Application, vol.6, pp. 82-84, Jun.2006.

[8] Li Juan, Xu Yu, Feng Gengzhong, Li Yixue, "An optimal decision study on staged loaning in warehouse financing", Operations research and management science, vol.16, pp. 9-13, Jan.2007.

[9] Li Yixue, Xu Yu, Feng Gengzhong, "Domestic and foreign researches on the evolution of inventory financing", Research on economics and management, pp. 22-26, Mar.2007. 